revert to the puppy coat with a much lower cystine content than the adult hair ${ }^{13}$.

We have experiments in progress designed to test the validity of our hypothesis. It is, unfortunately, too early as yet to cite results, but these will be presented without delay as soon as they become available. Claude Rrmington.

\section{J. G. BEKKER.}

J. KrLLerRmanN.

Onderstepoort Veterinary Research Laboratory, Pretoria, South Africa. March 8.

1 Rimington and Bekker, Nature, 129, 687, May 7, 1932

2 Aitken, Biochem. J., 24, 250; 1930

${ }^{3}$ Evans, J. Agric. Sci., 21, 806; 1931.

"Henrici, Eighteenth Report Dir. of Vet. Services and Animal Ind. Pretoria, August 1932, p. 579.

${ }_{5}^{5}$ Woodman and Evans, NATURE, 130, 1001, Dec. 31, 1932

6 Haag, $J$. Nutr., 4, 363; 1931.

? Bechdel, Honeywell, Dutcher and Knutsen, J. Biol. Chem., 80 $231 ; 1928$,

${ }^{8}$ NATURE, 129, 161. Jan. 30, 1932

Zschesche, Chem. $Z$., 56, $166 ; 1932$.

10 Sugata and Koch, Plant Physiol., 1, 337; 1926.

11 Weichselbaum, Weichselbaum and Stewart, NATURE, May 28, 1932 , p. 795.

12 Fraser and Roberts, NATURE, 130, 473, Sept. 24, 1932.

13 Lightbody and Lewis, J. Biol. Chem., 82, 663; 1929.

\section{Lability of the 'Reducing Factor' (Vitamin C?) in Milk}

For some time past the effect of various factors on the vitamin content of milk of a 'typical' English herd has been under investigation in this Institute. In the course of this work an endeavour has been made to measure the rather low vitamin $C$ potency of milk, using guinea pigs for the biological test.

Recently Tillmanns's chemical test ${ }^{1}$ for vitamin C as modified by Birch, Harris and $\mathrm{Ray}^{2}$ has been applied by us to this 'typical' milk, that is, to mixed samples of evening and of morning milk of our herd. of shorthorns, the diet and management of which is typical of the agricultural practice in the south of England, and also to morning's milk as put out for sale by our experimental dairy; lastly to morning's

Whatever its nature, it is evident even from the figures shown in the table that the quantity of the substance (or substances) in milk responsible for the reduction of the chlorophenol-indophenol reagent is subject to marked and irregular fluctuations. In this respect our findings are in agreement with those recently published by Schlemmer, Bleyer and Cahnmann ${ }^{3}$, who use a somewhat different method of precipitation and titration, but whose published figures show similar irregularities. If - and the weight of evidence is at present in favour of such a viewthis substance is identical with vitamin $\mathrm{C}$, it would appear that, under existing conditions, the presence of vitamin $\mathrm{C}$ in reasonable amounts cannot be guaranteed even in very fresh milk samples of high quality produced under first class conditions of feeding and management.

Under natural conditions milk is always in contact with living tissue, and passes direct from mother to suckling without change of temperature or exposure to air. The rapid disappearance of the reducing substance (whatever its nature) emphasises the suddenness with which a train of changes sets in in milk as soon as it leaves the udder.

We are at present engaged in a further study of the dynamics of this extremely labile system in milk.

National Institute for Research

S. K. KoN. in Dairying,

Shinfield, Nr. Reading. June 1.

${ }^{2}$ Z. Unters. Lebensmittel, 60, 34; 1930； Biochem. Z., 250, 312 ! 1932.

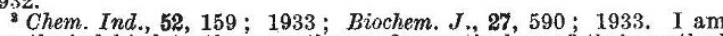
greatly indebted to these gentlemen for particulars of their method before publication.

${ }^{3}$ Biochem. Z., 254, 187; 1932.

\title{
Double Refraction of Oriented Surface Layers
}

WE have extended the scope of a method recently described $^{1}$ for the measurement of refractive indices of liquids in thin films, and have obtained evidence of the double refraction of the interfacial layer between melted normal fatty acids and glass. Acids with more than ten carbon atoms in the chain are being examined. The birefringence is small, usually less than 0.0001 , and exists only over a narrow tem. perature range of a few degrees immediately above the solidification point of the acid. This provides optical evidence that the molecules of the fatty acids are oriented at a glass-liquid interface to a depth comparable with a wave-length of visible light ${ }^{2}$. The sharpness of disappearance of the birefringence at a critical temperature is thought to indicate that the

milk of individual cows. Some of the data are given in the accompanying table, in which the figures shown represent the number of cubic centimetres of the trichloracetic acid filtrate from milk necessary to decolourise 0.05 c.c. of a 0.1 per cent solution of $2 \cdot 6$ dichlorophenol-indophenol; that is, the presumptive vitamin $\mathbf{C}$ content of the milk is proportional to the reciprocal of the titration figures. The 'type milk' was titrated in the morning within one hour of delivery from the dairy. This milk was made up of two parts evening's milk approximately 16 hours old and three parts morning's milk, approximately 1 hour old. Bottles of sale milk were left in the retail crates until needed for titration. anisotropic layer is a new phase, and that the fatty acid behaves as a 'liquid crystal' immediately above its solidification point.

The results of the work are shortly to be published in the United States, but meanwhile we take this opportunity of thanking Prof. E. K. Rideal, of Cambridge, who suggested that the problem would repay our attention.

A. M. TAYLOR.

Institute of Applied Optics, Alien King.

University of Rochester, N.Y. June 6.

1 Taylor and Glover, J. Optical Soc. Amer, 23, June 1933.

2 Trillat, J. Phys. Radium, 10, $32 ; 1929$. 